\title{
Operational flood forecasting and warning under the changing environment in China
}

\author{
Zhiyu Liu \\ Information Center, Ministry of Water Resources of China, Beijing, 100053, China \\ Correspondence: Zhiyu Liu (liuzymwr@163.com)
}

Published: 16 September 2020

\begin{abstract}
Flooding has been the most severe hazard in China from time immemorial, due to its special geographical, climatic and socio-economic conditions. In recent years, against the background of global climate change and rapid urbanization, extreme hydro-meteorological events have obviously increased in China, in turn affecting the sustainable social and economic development. This paper analyses how modern flood risk management has evolved from the early "build and protect" flood control approach to a broader flood risk management approach by analyzing what has happened in China and the role of major floods in this evolution. The development of flood forecasting models and systems in terms of how they have informed decision-making as flood risk management has evolved over the years. The challenging of recognizing and dealing with forecast uncertainty and flood risk in decision-making is also analyzed in the paper.
\end{abstract}

\section{Introduction}

Floods are the most frequent and serious natural disasters in China. Although a few floods in west China are subject to the mixed-type floods from snow and glacier melting as well as local storms, the majority of floods in China are caused by rainstorms in combination with the coastal storm surges. According to historical records, big flood disaster events averaged once every two years before 1949. Beginning from the twentieth century, many flood fatalities have been recorded in China. In 1931, disastrous floods hit the Huaihe River basin and the Yangtze River basin, affected over 51 million people and caused 400000 deaths (SFCDRHO, 2010). The average annual death toll in recent floods indicates a decreasing trend from 8571 (1950s) to 875 (2010s) as flood control systems have been improved significantly since 1950 (MWR, 2018).

It is the exponentially increasing impact of flooding that has raised the profile of the practice of flood forecasting and warning. Since the late 1980s there has been a move away from the primacy of major structural measures for flood control towards a more integrated approach, of which flood forecasting and warning is a component. The Integrated Flood Management Concept encourages a shift from the traditional, fragmented and localized approach, towards the use of the resources of a river basin as a whole, while at the same time provides protective measures against losses due to flooding (Arduino et al., 2005; Linnerooth-Bayer and Amendola, 2003).

Due to global warming, social and environment changes, and climate systems, flooding is becoming more extreme, more widespread and more frequent in China, increasing the risks and the costs of flood disasters (Wu et al., 2013). This has given rise to increased emphasis on the improvement of operational flood forecasting and warning, and the enhancement and refinement of flood-risk (understood as a product of probability and consequences) management systems.

This paper presents an overview of Chinese experiences in coping with floods and gives lessons from disastrous flood events. The paper also describes the development of hydrological forecasting and prediction technology and methods that support flood management in China, focusing on recent advances in flood forecasting and warning. Furthermore, challenges and expectations in China's flood forecasting and warning are also presented in the paper. 


\section{Evolution of flood control and management under the changing environment in China}

For thousands of years, China has suffered greatly from flooding on large and small rivers. Before the founding of the P. R. China in 1949, big flood occurred in China once in every two years with serious loss. In 1933, the Yellow River levee was breached at over 50 locations flooding and more than 3.6 million people suffered, of which18 thousand people died. After 1949 big floods occurred in large rivers (e.g. the Yangzte-Huaihe Rivers Flood in 1954, the Songhua River Flood in 1957, the Yellow River Flood in 1958, the Haihe River Flood in 1963, the Upper Huaihe River Flood in 1975, the Great Flood in 1998, and so on), yet the losses were far less serious because of the role of the completed flood control projects and that great efforts were made in flood fighting. For example, in the summer of 1954, big floods occurred over the Yangtze River Basin. The water level in the main stream of the Yangtze reached the highest record. The Jingjiang Flood Diversion Works and Dongting lake were to divert and store flood water. The city of Wuhan was protected.

Since 1949, the government has attached high significance to the prevention and control of floods. Continuous efforts have been exerted to summarize experiences and lessons from major flood events and the role played by innovative work mechanisms, enhancement of structural development, improvement of non-structural measures and this has led to remarkable progress in capacity building for flood prevention and management. The accomplishments of China in this regard during the past 7 decades encompass the following three phases of flood control and management.

\subsection{Start-up phase: before the mid-1970s}

The 1950s and 1960s saw increasing efforts to harness major rivers, control and prevent floods. In 1950, the State Flood Control Headquarters and the Yellow River Flood control Headquarters were formally established, followed by the setting up of the Yangtze River Flood Control Headquarters and some key provincial flood control headquarters in succession. During this period, based on the principles of attaching equal importance to enhancing flood-water storage and discharge capacity, with the emphasis on the latter, the comprehensive management planning for the Huaihe River, the Yellow River, the Yangtze river, and the Haihe River basin have been successively carried out, which laid a solid foundation for harnessing rivers afterwards. Moreover, an engineering system for flood control has been preliminarily constructed, including the construction of trunk embankments for protecting major rivers, building numbers of large and medium-sized reservoirs, completing flood storage and detention areas on major rivers and progressively training major rivers.

\subsection{Development phase: from the mid-1970s to 1998}

In August of 1975, the Great Flood of the Huaihe River caused by the heavy rainstorm and dam-failures, devastated Henan province, killing 26000 people (SFCDRHO, 2010). A subsequent profound reflection on the "75.8" flood led to the transition towards a broader, comprehensive flood management approach where the emphasis shifted from engineering measures to a broad portfolio of structural and non-structural measures for managing flood risk. From this time onward, the national specification on design flood estimation was revised, and the standard of flood control projects has been significantly enhanced. Besides, investment on the water conservancy has been progressively increased, with the emphasis on dyke reinforcement and renovation on major rivers, danger control and reinforcement of dangerous reservoirs by stages and in groups, construction of flood storage and detention areas with a view to guaranteeing the safety of people living there. By 1998, continuous efforts have been made to improve the non-structural measures including development of early warning and forecasting systems, formulating flood disaster preparation plans, improvement of the legal framework, establishing the administrative leader responsibility system, strengthening the organizational and institutional system, and setting up flood relief rescue teams.

\subsection{Improvement phase: from 1998 to the present day under the changing environment}

In 1998, the most devastating floods occurred in some major rivers such as the Yangtze, Songhuajiang, Pearl and Min Rivers, which left over 4000 people dead and caused material damage of USD 30 billion (SFCDRHO, 2010). In the aftermath of the Great Flood of 1998, the central government launched the strategic plan encompassing post-disaster reconstruction, renovation of rivers and lakes, start construction of water conservancy, and developed the water governance policy, namely overall planning and comprehensive treatment, promoting what is beneficial and abolish what is harmful, attaching equal importance to increasing income and reducing expenditure, and putting equal emphasis on flood-control and anti-drought. Thus, flood control work entered a new period of development.

The flood risk concept was introduced and gradually applied in flood management in China. In 2003, the China Ministry of Water Resources proposed to re-direct flood prevention from flood control to flood management, which aims to enhance understanding about interconnecting systemic issues and risk awareness. The flood prevention efforts thus shifted from attempts to eliminate floods forward to building capacity to endure floods with certain degrees of risk. In flooding areas, community management was introduced to regulate human activities. Meanwhile, efforts were also taken to utilize storm water as a complementary resource for water supply. 
In recent years, against the background of global climate change and rapid urbanization, extreme hydrometeorological events have obviously increased in China. Local storms, sudden flash floods, urban water-logging, extreme high temperature drought and super typhoon events occurred in a sudden, more frequent and concurrent manner. For example, from 9 to 11 August 2007, affected by two typhoons, an extreme storm event hit the Leizhou Peninsula on the western part of Guangdong Province; the 24hourly rainfall reached $1188.2 \mathrm{~mm}$, a new heavy rainstorm record in China. Floods happened in 2010 were the worst since 1998, which big investment in flash-flood prevention and harnessing of medium and small rivers. On 12 July 2012, a rarely-seen rainstorm hit Beijing. The daily rainfall reached one quarter $(1 / 4)$ to one third $(1 / 3)$ of the yearly total. The mean areal rainfall is $170 \mathrm{~mm}$, a historical record since the year 1949. In the rainstorm center, Hebei Town of Fangshan District, the rainfall reached $541 \mathrm{~mm}$, and the recurrence interval is 500 years. Moreover, from 7 to 12 July 2013, an extreme rainfall process appeared in northern Sichuan Province of China, and the accumulated rainfall is $1151 \mathrm{~mm}$ in Dujiangyan City, with a recurrence interval of 100 years. These extreme rainstorms resulted in disastrous floods of riverine floods, flash flooding and urban water-logging.

Research shows that the increased frequency and intensity of flooding in typical southern river basins with high flood risk, and small and medium-sized rivers became prominent, and urban flooding and water-logging caused by storms in metropolises showed an increased trend. Heavy rain, floods and other extreme events may increase in occurrence and in intensity in future in parts of China, so as to increase the risk of flood disasters and accelerate the difficulty of floodprevention and dispatch command, and thus causing unfavorable influences on the economic and social sustainable development.

\section{Development of operational flood forecasting and warning in China}

In response to the changing environment, the hydrological services in China have taken efforts in enhancing the monitoring network, strengthening monitor over emergency water events, and improving the monitoring, forecasting and warning in support of flood risk management in the country.

\subsection{Hydrological monitoring}

Hydrological monitoring stations in China are divided into two types: state level basic stations and special stations. By the end of 2018, there are 113245 hydrometric stations maintained by the water sector in China, including 7102 hydrological stations (3148 state-level basic hydrological stations), 13579 water level stations, 54477 rainfall stations, 2571 soil moisture stations, 19147 groundwater monitoring stations, among which there are 59104 flood-reporting stations and 2100 flood forecasting sites.

At present, hydrological observation items include precipitation, evaporation, stage, discharge, sediment, water quality, ground water, water temperature, ice slush etc. The types of hydrological stations in China include perennial stationary gauging, stationary gauging during flood season, full-year touring gauging and entrust gauging etc. The discharge measurement is done mainly by using cableway and hydrometric boat. Current-meter method is commonly used for discharge measurement while the float method, discharge calculation by hydraulic method, flow measurement by hydraulic structure are used in the case that ordinary hydrometry facilities are destroyed due to major floods. Presently, some new techniques and methods such as the moving-boat method by using Acoustic Doppler Current Profiler (ADCP) are being applied to flow measurement in China.

\subsection{Hydrological data transmission}

Real-time hydrological information are transmitted by means of GSM, GPRS and telephone, satellite, transmitter-receiver to local information centers, and then transferred to regional information centers and the Information Center of MWR, through Wide Area Network (WAN). The information are automatically received, processed and stored by computer system.

Hydrological information transmission technology in China has been improved. By 1995, the traditional telegraph transmission way has been replaced by public packet switched data network (CHINAPAC X.25) to achieve a countrywide real-time hydrological information transmission by WAN. By 2005, based a wide band network of 2 Mbps, using hydrological information code way, the real-time hydrological information has been transmitted rapidly. By 2011, the Hydrological Information Transmission System replaces the hydrological information code way to realize a comprehensive and efficient transmission for hydrological information. At present, over $80 \%$ of the hydrological stations measure and report information in an automatic way, about $98 \%$ of the hydrological information from the hydrological stations can be transmitted to Information Center, MWR, within $15 \mathrm{~min}$.

\subsection{Hydrological forecasting method and model}

The constraints of hydrological data availability and computer science in the past limited China's hydrological forecasting methods to those based on experience. In the 1960s, hydrologic models started to be developed and applied following the introduction of mathematical simulation into the field of hydrology. China focused on bringing in suitable hydrologic models and developing those to be applicable to local hydrological conditions. Currently there are basically two types of hydrological forecasting methods: empirical hydro- 
logical forecasting method and that using conceptual hydrologic models.

The empirical hydrological forecasting method comes from the experiences that hydrological practitioners gathered over a long time, and this proves to be very effective in operational hydrological forecasting. At present, the 7 major river basin authorities in China have compiled complete empirical hydrological forecasting schemes, and the 600 plus hydrological forecasting stations in China have nearly 1000 schemes. In general, the empirical hydrological forecasting schemes apply such methods as antecedent precipitation index (API), corresponding stage (discharge) method, resultant discharge method, stage (discharge) fluctuating rate method, multi-factors combined axes correlation method, rainfall runoff correlation method, and so on.

China has extensive territories, with varied underlying surface conditions and different climates such as humid, dry, semi-humid and semi-dry climates. For decades, Chinese hydrologists have made efforts to learn from international hydrologic models and succeeded in developing a series of river basin hydrologic models applicable to local conditions. The Xin'anjiang model proposed by Zhao Renjun in 1973 is the representative model that was developed. The main feature of the model is the concept of runoff formation on repletion of storage, which means that runoff is not produced until the soil moisture content of the aeration zone reaches the field capacity, and thereafter runoff equals the rain fall excess without further loss. The model can be used for real time flood forecasting, investigations for gaining understanding of hydrological processes and study of the impacts of land use change on runoff, etc. Nowadays, hydrologic models used in operational hydrological forecasting in China comprise three types: those developed by Chinese professionals, international models and adapted international models. Locally developed models include examples of the Xin'anjiang model (Zhao et al., 1980; Zhao, 1992; Zhao and Liu, 1995), the double excess runoff yield model, the Hebei storm flood model, the Jiangwan Bay runoff model and the double attenuation curve model. Tank, Sacramento, NAM and SMAR are major international models that are used, while the continuous API model and SCLS model were also introduced and modified to adapt to local conditions (WMO, 2011).

In recent years, environmental changes brought challenges to hydrological forecasting and warning. Distributed hydrological models based on underlying terrain geographic information were developed and started to be used in flood forecasting and warning for flash floods as well as medium-small river flooding. Besides, the concept of dynamic critical rainfall index based on soil moisture was developed, and has been applied to medium-small rivers for flash flood early warning.

\subsection{Hydrological forecasting systems}

The computer science and network technology are indispensable for the development and application of Chinese hydro-
Table 1. Flood forecasting models employed in the CNFFS.

\begin{tabular}{ll}
\hline No. & Name \\
\hline 1 & Xin'anjiang Model \\
2 & API Model \\
3 & Jiangwan Runoff Model \\
4 & Hebei Storm Flood Model \\
5 & Shanbei Model \\
6 & Xin'anjiang Model for Semiarid Area \\
7 & Liaoning Model \\
8 & Double Attenuation Curve Model \\
9 & Double Excess Runoff Yield Model \\
10 & SMAR Model \\
11 & NAM Model \\
12 & Tank Model \\
13 & Sacramento Model \\
14 & SCLS Model \\
15 & Index Recession Method \\
16 & Recession Curve Method \\
17 & Unit Hydrograph Method \\
\hline
\end{tabular}

logical forecasting systems. In the early 1980's, China developed the real-time flood forecasting system run on the VAX machines and on a single computer. As the consequence of the limited database management and software development technology at that time, data were mostly managed in a file system and on-line operational forecasting was at a very low level with very simple functions, mainly programming existing forecasting schemes and models. From 1990 onward, hydrologists in China learned from peers in developed countries with more mature and advanced technologies, and achieved progress in developing forecasting systems with functions of database management, model parameter calibration and optimized calculation, operational forecasting, real-time forecast updating, and visualized data and forecasting results. After the 1998 Great Flood, the Chinese hydrological sector made efforts to enhance the hydrological monitoring capacity and develop the universal flood forecasting system software platform: China National Flood Forecasting System (CNFFS) (Zhang and Liu, 2007). The CNFFS consists of three major components in a calibration system, operational forecast system and extended stream flood prediction system, which are shown in Fig. 1. The CNFFS contains common forecasting models and a method library allowing prompt building of forecasting schemes. Many different flood forecasting models are employed in the system, including the Xinanjiang model, and other models such as API, Sacramento, Tank, SMAR, and the synthetic constrained linear system (SCLS), as listed in Table 1.

Most large reservoirs and key medium-sized reservoirs built for flood prevention purpose have established telemetry systems, flood forecasting and regulation systems. The CNFFS has been successfully used in 33 flood forecast cen- 


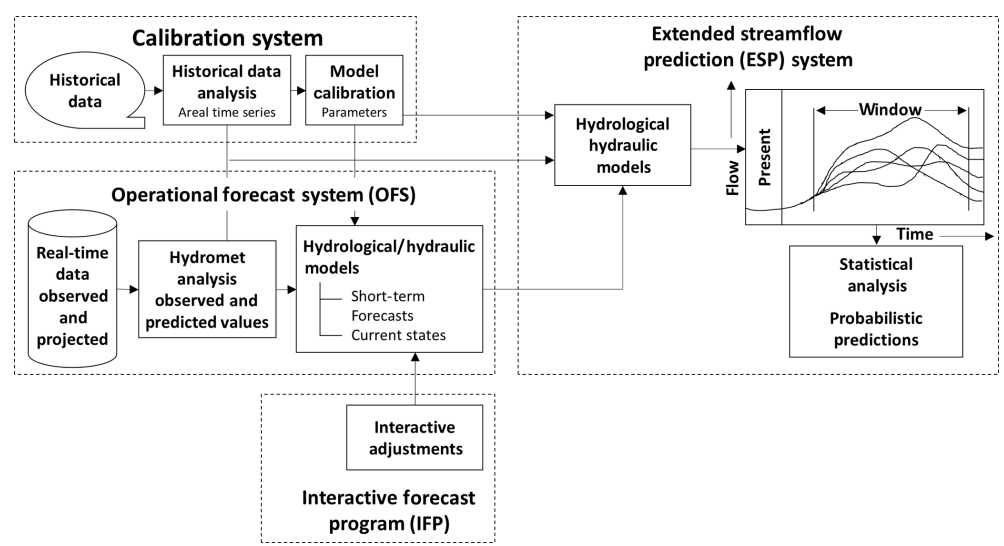

Figure 1. Overall structure chart of China National Flood Forecasting System.

ters at national, river-basin and provincial levels in support of flood management in the country.

\subsection{Application of new technology in flood forecasting and warning}

The scientific and technological development in recent years enables China to apply new and advanced technology to the hydrological forecasting, which improves the forecasting software and operational forecasting accuracy. The following are three representative examples.

\subsubsection{Application of NWP-Based QPF in flood forecasting and reservoir operation}

In real-time operational forecasting, the rainfall and flood joint forecast technology applies satellite and radar images for quantitative precipitation estimation (QPE), NWPs for QPF. In the first step, the meteorological department provides data needed by the hydrological department for rainfall forecasts and prediction in terms of location, quantity and time. The next step is the flood forecast. The results of the two steps are then combined to improve the lead time and prediction accuracy of hydrological forecasting and prediction. Recently, the availability of multiple NWP models from various weather services such as China Meteorological Administration, Japan Meteorological Agency, European Centre for Medium-Range Weather Forecasts (ECMWF), offers an opportunity for the development of hydro-meteorological coupling and flood forecasting and operation coupling systems in China, and this approach has been proved successful in operational application. The Three Gorges reservoir experienced three major floods in the summer of 2010. In July 2010, it reached a flood peak of $70000 \mathrm{~m}^{3} \mathrm{~s}^{-1}$ exceeding the peak in 1998 Yangtze River Floods. During that time, national hydrological forecasting service issued a timely, accurate flood forecasting $2 \mathrm{~d}$ in advance, which was performed by combining NWPs with national flood forecasting system.

\subsubsection{Application of distributed hydrological models for flash flood forecasting}

More recently, deterministic spatially distributed hydrologic models have been gradually used in China. Based upon equations representing the storage and the movement of water in the soil and on the surface, distributed models are potentially easier to calibrate by relating the values for their physically meaningful parameters to additional information provided in the form of Digital Elevation Maps, Soil Maps and Land Use Maps. These models account for the spatial distribution of rainfall (now available at pixels of between $1 \times 1$ and $10 \times 10 \mathrm{~km}$ from RADAR images or in terms of QPF from NWP models) and are better equipped to address the problem of extrapolating the parameter values to the un-gauged sub-catchments, a problem that has not yet found a proper solution. All these potential properties, combined with the increased efficiency of computers, have given rise to a number of fully distributed rainfall-runoff models, some of which, for instance, the TOPKAPI model (Liu et al., 2008), have been incorporated into real time flood forecasting systems, and applied to flash flood forecasting and warning in a number of medium and small sized rivers in Jiangxi, Hunan, Hubei, Anhui, Zhejiang, Henan, Shanxi provinces (Liu et al., 2015).

\subsubsection{Application of RS technology in flood monitoring and forecasting}

Recently, RS technology with medium and high-resolution data has been widely used in China in water resources monitoring and evaluation and management, flood and drought monitoring and prediction, and soil and water conservation monitoring and evaluation. Recently, RS data of MODIS, HJ, HS-1, NOAA/AVHRR, NPP/VIIR, SPOT, Landsat-2 have been of operational use in China, e.g. in the Great Flood of Heilongiiang River in 2013. After the levee breach happened, water levels at the downstream of the River stopped rising. The question raised for forecasters is "how big is the discharge from the breach, and will the water level on down- 
stream will rise further? If it goes up again, how much?" In this case, the accurate water forecast analysis is directly related to the flood control scheme and the scientific decisionmaking. Through RS technology and DEM data analysis, the hydrological department continuously monitors the submerged area, water depth and water volume, estimates the discharge from the breath and inundated water-volume, and then predicts the flood peak water level of the downstream, providing important information support for the decisionmaking and deployment for flood control and emergency response.

\section{Conclusions and outlook}

Flood disasters in the past decades have become more frequent and devastating in China. The Chinese Government gives high priority to flood management through both structural measures and non-structural measures with the aim of improving capacity and level of flood disaster prevention and mitigation. As the most significant non-engineering measure for flood control and disaster reduction, flood forecasting and warning plays an important role in support of decisionmaking for masses evacuation, rescue and relief, reservoir optimum operation, emergency response etc., bringing eminent economic and social benefits.

Entering 21st century, flood forecasting and warning shall be further applied to agriculture and rural areas, city construction, traffic transportation, tourism and other industries, for flood disaster prevention and mitigation, water resources management, economic and social development and other water-related activities to provide more comprehensive and accurate information services.

It is anticipated that impact-based flood forecasting and warning will be developed in the future in China. Flood forecasting must be done to predict the possible impacts of flood and water-logging on rivers, lakes and reservoirs, cities, transportation and agriculture, etc., realizing the transition from hydrological forecasting to disaster impact forecasting, from making hydrological forecasts at sites, to simulating hydrological cycle process at sites, flood propagation along rivers, and flood inundation mapping. The probability of occurrence of flood and water-logging disasters will be forecasted, and the flood security risk of reservoirs, industry and agriculture production, city transportation and other objectives can be assessed, linking together hydrological forecasts of discharge with high resolution flood mapping, and realizing the transition from the threshold-based flood warning to the risk-based flood warning. Meteo-hydrological ensemble prediction and multi-model based probability forecast technology will be employed for this purpose.

Data availability. No data sets were used in this article.
Competing interests. The authors declare that they have no conflict of interest.

Special issue statement. This article is part of the special issue "Hydrological processes and water security in a changing world". It is a result of the 8th Global FRIEND-Water Conference: Hydrological Processes and Water Security in a Changing World, Beijing, China, 6-9 November 2018.

Financial support. This study was supported by the National Key Research and Development Program of China - study and application of key technologies for flood control and emergency management of small and medium-sized rivers (grant no. 2018YFC1508100).

\section{References}

Arduino, G., Reggiani, P., and Todini, E.: Recent advances in flood forecasting and flood risk assessment, Hydrol. Earth Syst. Sci., 9, 280-284, https://doi.org/10.5194/hess-9-280-2005, 2005.

Linnerooth-Bayer, J. and Amendola, A.: Introduction to special issue on flood risks in Europe, Risk Anal., 23, 537-543, 2003.

Liu, Z., Tan,B., Tao, X., and Xie, Z.: Application of a distributed hydrologic model to flood forecasting in catchments of different conditions, J. Hydrol. Eng., 13, 378-384, https://doi.org/10.1061/(ASCE)1084-0699(2008)13:5(378), 2008.

Liu, Z., Hou, A., and Wang, X.: Flood forecasting technology for medium and small rivers based on distributed hydrological model, J. China Hydrol., 35, 1-6, 2015.

MWR - Ministry of Water Resources: Bulletin of flood and drought disasters in China 2017, China Water Power Press, Beijing, 8284, 2018.

SFCDRHO - The State Flood Control and Drought Relief Headquarters Office: Training materials for specialized cadres in flood control and drought relief, China Water Power Press, Beijing, 16-17, 2010.

WMO: Manual on Flood Forecasting and Warning, WMO Publication No. 1072, World Meteorological Organization, 142, 48-49, https://doi.org/10.1016/j.transproceed.2010.08.027, 2011.

Wu, Z. Lu, G., Liu, Z., Wang, J., and Xiao, H.: Trends of extreme flood events in the pearl river basin during 1951-2010, Adv. Clim. Change Res., 4, 110-116, 2013.

Zhang, J. and Liu, Z.: Hydro-meteorological monitoring and operational hydro-systems for flood management in China, in: IAHS Publ. 311, Proceedings of the International Symposium on Methodology in Hydrology, Nanjing, China, 3-9, 2007.

Zhao, R. J.: The Xinanjiang model applied in China, J. Hydrol., 135, 371-381, https://doi.org/10.1016/0022-1694(92)90096-E, 1992.

Zhao, R. J. and Liu, X. R.: The Xinanjiang model, in: Ccomputer models of watershed hydrology, edited by: Singh, V. P., Water Resources Publications, 215-232, 1995.

Zhao, R. J., Zhuang, Y. L., Fang, L. R., Liu, X. R., and Zhang, Q. S.: The Xinanjiang model, in: Hydrologica Forecasting Proceedings Oxford Symposium IAHS, 129, 351-356,1980. 